AJHSE Vol: 2 (2): 154-164, 2021

DOI: $10.52417 /$ ajhse.v2i2.170

Accepted Date: Sept. 30, 2021

(C) 2021. CC License 4.0

www.ajhse.org

CrossMark

\& click for updates
African Journal of Health, Safety and Environment

An official publication of the

Applied Environmental Bioscience and Public Health Research Group

University of Benin, Benin City, Nigeria

Open Access | Bi-annual | Peer-reviewed | International

ISSN (Online): 2695-1819 | ISSN (Print): 2695-2386

\title{
ACCESSIBILITY AND USE OF ANTIBIOTICS AMONG PATIENTS VISITING COMMUNITY PHARMACIES IN BENIN CITY, NIGERIA
}

\author{
${ }^{*}$ Isabel, N. A., ${ }^{2}$ Efe, A. E. \& ${ }^{3}$ Joshua, O. I. \\ ${ }^{*}{ }^{2 \& 3}$ Department of Clinical Pharmacy \& Pharmacy Practice, Faculty of Pharmacy, University of Benin, Benin City, Nigeria \\ *Corresponding Author's E-mail: isabel.aika@ uniben.edu Phone: +2348082826539
}

\begin{abstract}
ntibiotic resistance is an increasing problem worldwide. Among contributory factors is increasing easy 1 the accessibility and use of antibiotics. A descriptive cross-sectional study was conducted in eight community pharmacies in Benin City, Nigeria. A structured questionnaire was used for data collection. Administrative approval was obtained from the superintendent pharmacists, while informed consent was sought from all study participants. The data obtained from the study were analyzed using IBM SPSS version 22. Of the 450 participants in the study, most [329 (73.11\%)] had used antibiotics in the last six months before their current visit to the pharmacy, 207 (46\%) of them took the antibiotic without laboratory investigation. Many [274 (60.89\%)] of the participants had an antibiotic among the medications they got from the pharmacy on their current visit. More than half [289 (64.22\%)] of the participants sometimes got antibiotics without prescription. More Pharmacists recommended antibiotics for participants compared to doctors (44.11\%: $24.44 \%$ ), while more than half of the study population (62.89\%) got their antibiotics from pharmacies. Many [295 (65.56\%)] of the participants think that the country should regulate antibiotic use. This study has shown that community pharmacy is a major outlet where patients source antibiotics sometimes without a prescription, thus denoting that many patients self-medicate with antibiotics. The need for incorporating community pharmacists in developing guidelines for prescribing and using antibiotics is crucial.
\end{abstract}

Keywords: Antibiotics, Pharmacists, community pharmacy, Patients, Accessibility

LICENSE: This article by African Journal of Health, Safety and Environment (AJHSE) is licensed and published under the Creative Commons Attribution License 4.0 International License, which permits unrestricted use, distribution, and reproduction in any medium, provided this article is duly cited.

COPYRIGHT: The Author(s) completely retain the copyright of this published article.

OPEN ACCESS: The Author(s) approves that this article remains permanently online in the open access (OA) model

QA: This Article is published in line with "COPE (Committee on Publication Ethics) and PIE (Publication Integrity \& Ethics)". 


\section{INTRODUCTION}

World Health Organization estimated that about $20-50 \%$ of antibiotics used worldwide are either used or prescribed inappropriately (WHO 2001; 2015). The remarkable effectiveness of antibiotics leads to their widespread usage, and a persistent belief among the general public that antimicrobials are universally efficacious and should therefore be applied in the first instance to virtually all ailments. The belief in the universal applicability of antimicrobials has resulted in their exuberant use and so has applied a widespread, strong, and polarized selective pressure on the microbial world. This has resulted in the increasing rates of antibiotic or antimicrobial resistance (AMR) seen today (Carolyn et al., 2014). Antibiotic resistance is rising to dangerously high levels in all parts of the world. New resistance mechanisms are emerging and spreading globally, threatening our ability to treat common infectious diseases. A growing list of infections such as pneumonia, tuberculosis, blood poisoning, gonorrhea, and foodborne diseases are becoming harder, and sometimes impossible, to treat as antibiotics become less effective (WHO 2017). Where antibiotics can be bought for human use without a prescription, the emergence and spread of resistance is made worse. Similarly, in countries like those in low- and middle-income regions, without standard treatment guidelines, antibiotics are often over-prescribed by health workers and veterinarians and over-used by the public (WHO 2017; Carolyn et al., 2014). In developing countries, antibiotics can be readily purchased without any control; such countries usually experience more cases of AMR, in contrast to what occurs in western nations where tight regulations of antibiotic use are in place. Self-medication practices have a major pitfall, which is that users do not follow a prescribed course of drug dosage and usually stop the drug regimen once they are relieved of symptoms of illness (Ayukekbong et al., 2017).

In Nigeria, there is poor regulatory control of antibiotic sales, and purchases can be carried out without the prescription of a clinician. In addition, there is a preponderance of counterfeit drugs in the market which makes it difficult to achieve effective treatment of self-diagnosed illnesses thus increasing the propensity for more use of antibiotics (Olumide et al., 2018). This study aims to investigate the accessibility and use of antibiotics in community pharmacies in Benin City.

\section{METHODOLOGY}

Study setting/design: This was a Cross-sectional study carried out at different community pharmacies in four local government area of Benin City, Edo state of Nigeria. Four local government areas were used for this study. Different community pharmacies were selected using convenience sampling along the four local government areas of Benin City, Edo State. The different local government areas that were selected for this study are Ovia North east local government area, Egor local government area, Oredo local government area, and Ikpoba local government area.

\section{STUDY PARTICIPANTS}

Participants were clients or patients visiting selected community pharmacies and are above 18 years of age. All study participants were informed on study objectives and those who granted permission were recruited for the study. Administrative approval was obtained from the superintended pharmacist of the visited community pharmacy.

\section{DATA COLLECTION}

A structured interview questionnaire was used for data collection. The questionnaire had three sections. The first section was used to collect information on patients demographics, while the second and third sections were used to 
obtained information of patient knowledge and attitude on different antibiotics used, different medical condition that warrant the usage of the antibiotics and assessment of patients knowledge on antibiotics resistance.

\section{DATA ANALYSIS}

The data obtained from the survey were entered into Microsoft excel and transferred in IBM SPSS version 22.

Descriptive statistical analysis was performed.

\section{RESULTS}

A total number of 450 respondents participated in the study, of which majority (55.33\%) were between the ages of 18-29 years. There was almost equal proportions of male (44.67\%) and female (49.78\%) participants in the study. About a third (33.33\%) of the respondents were unemployed. While about half $(47.56 \%)$ of the respondents had postsecondary education, other characteristics of the study participants are as shown in Table 1.

Table 1: Social Demographic of Respondents

\begin{tabular}{ll}
\hline Variables & \multicolumn{1}{c}{ Frequency (Percentage) } \\
& N (\%) \\
\hline Age (years) & \\
$18-29$ & $249(55.33)$ \\
$30-39$ & $68(15.11)$ \\
$40-49$ & $66(15.11)$ \\
$50-59$ & $44(9.78)$ \\
$\geq 60$ & $20(4.44)$ \\
Sex & \\
Male & $201(44.67)$ \\
Female & $224(49.78)$ \\
Level of education & \\
No formal & $25(5.55)$ \\
Primary & $27(6.00)$ \\
Secondary & $69(15.33)$ \\
Post-secondary & $214(47.56)$ \\
Occupation & \\
Government Sector & $65(14.44)$ \\
Private Sector & $92(20.44)$ \\
Self employed & $125(27.78)$ \\
Umemployed & $150(33.339)$ \\
Retired & $(2.00)$ \\
Marital status & \\
Single & $297(66.45)$ \\
Married & $145(32.22)$ \\
Health Insurance & \\
Yes & $137(30.44)$ \\
No & $300(66.67)$ \\
\hline
\end{tabular}

More than half 274(60.89\%) of the respondents visiting community pharmacies at the time of this study had an antibiotic as part of medications in their prescription. When asked if they used antibiotics before their current visit to the pharmacy, many [204(45.33\%)] took antibiotics one month before, 207 (46\%) of those who took antibiotic did not do any laboratory investigation warranting the use of antibiotic. About half [185(44.1\%)] of those who had an antibiotic as a past medication history said a pharmacist recommended it for them compared to 110 (24.4\%) of the participants who got a doctor's prescription. The source of the antibiotics they used was mostly from pharmacy outlets 
$(62.89 \%)$ compared to $12 \%$ of the respondents who got their antibiotics from hospitals. More details are shown in Table 2.

Table 2. Responses on Past Antibiotic Use

\begin{tabular}{|c|c|}
\hline Variables & $\begin{array}{l}\text { Frequency (Percentage) } \\
\text { N }(\%)\end{array}$ \\
\hline \multicolumn{2}{|c|}{ Does your current visit to pharmacy/prescription include an antibiotic } \\
\hline Yes & $274(60.89)$ \\
\hline No & $164(36.44)$ \\
\hline \multicolumn{2}{|c|}{ When last did you take an antibiotic } \\
\hline A month ago & 204(45.33) \\
\hline In the last six months & $125(27.78)$ \\
\hline About a year ago & $19(4.22)$ \\
\hline More than a year & $20(4.44)$ \\
\hline Cannot remember & $79(17.56)$ \\
\hline \multicolumn{2}{|c|}{ On that occasion was test conducted to warrant antibiotic use } \\
\hline Yes & $207(46)$ \\
\hline No & $217(48.22)$ \\
\hline \multicolumn{2}{|c|}{$\begin{array}{l}\text { On the occasion who prescribed/recommended the } \\
\text { antibiotics }\end{array}$} \\
\hline Self-medication & $60(13.33)$ \\
\hline Patent medicine dealer & $32(7.11)$ \\
\hline Nurse & $37(8.22)$ \\
\hline Doctor & $110(24.44)$ \\
\hline Pharmacist & $185(44.11)$ \\
\hline \multicolumn{2}{|c|}{$\begin{array}{l}\text { On that occasion where did you get the antibiotics } \\
\text { prescribed }\end{array}$} \\
\hline Patent medicine store & $64(14.22)$ \\
\hline Hospital & $34(12.00)$ \\
\hline Pharmacy & $283(62.89)$ \\
\hline Left over antibiotics & $17(3.78)$ \\
\hline
\end{tabular}

Table 3 portrays ailments respondents took antibiotics for. Typhoid fever, urinary tract infection and malaria (24.44\%: $22 \%: 16.89 \%$ ) were top on the list for which participants used antibiotics to treat. 
Table 3. Ailment for which respondent use antibiotics

\begin{tabular}{ll}
\hline Variable & \multicolumn{2}{c}{ Frequency(percentage) } \\
& \multicolumn{1}{c}{$\mathbf{N}(\%)$} \\
\hline What do you usually take antibiotics for & $62(13.78)$ \\
Fever & $99(22.00)$ \\
Urinary tract infection & $66(14.67)$ \\
Cough & $76(16.89)$ \\
Malaria & $110(24.44)$ \\
Typhoid & \\
\hline
\end{tabular}

More than half [289 (64.22\%)] of the respondents sometimes get antibiotics without a prescription, while majority [295 (65.56\%)] of them recommended that regulation of antibiotics should be considered in Nigeria such that they are gotten only with prescription (Table 4).

Table 4. Accessing Antibiotics without Prescription

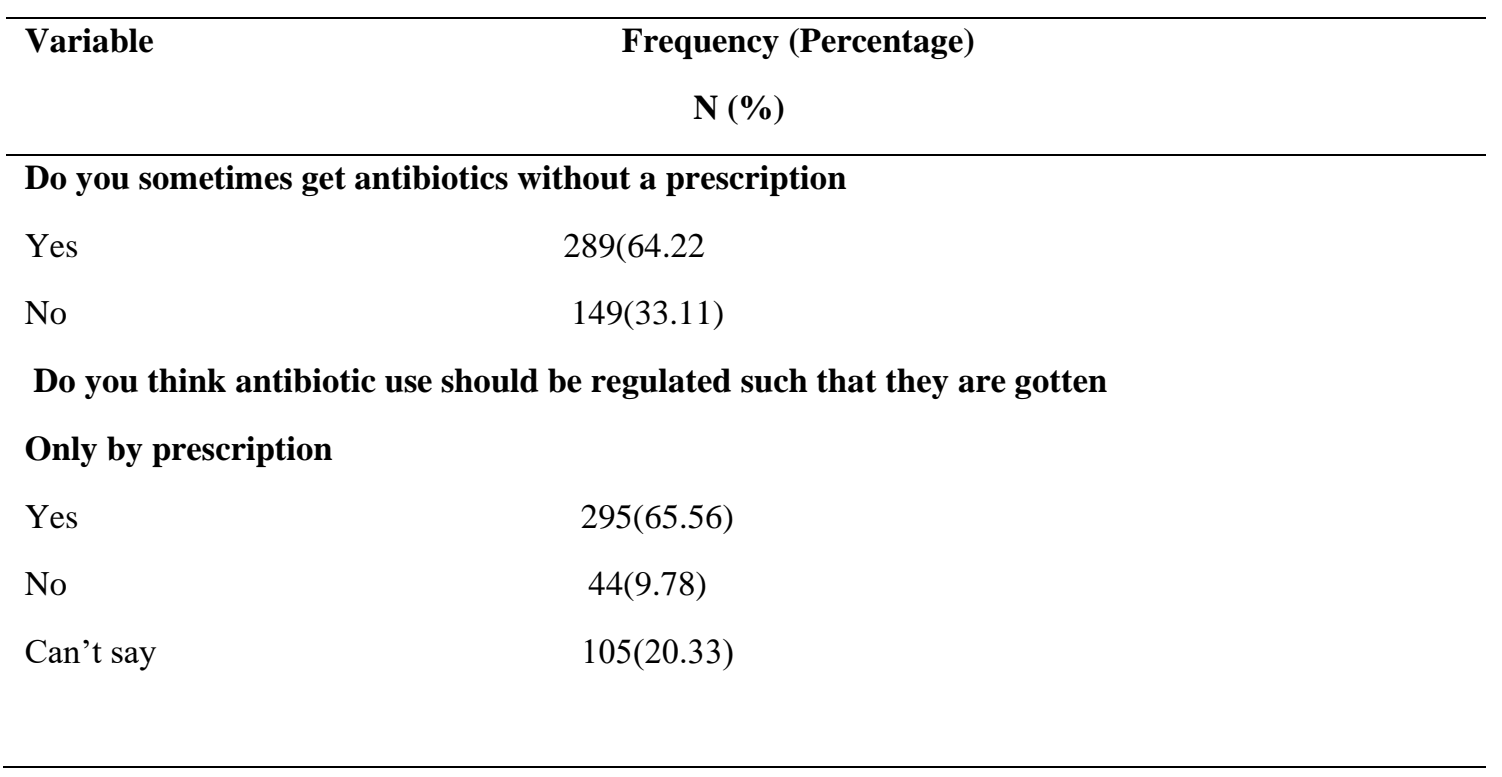

Respondents perception or attitude on antibiotics use as shown in Table 5 reveals that majority [ 326 (72.44\%)] of them usually adhere to instruction to finish dose of antibiotic, on the other hand, 205 (45.56\%) of the respondents buy antibiotics used for past ailments when similar symptoms present. Similar response from 241 (53.56\%) of the participants was given on using antibiotics taken by close relatives or friends who may have used an antibiotic for illnesses that mimic respondent's complaint. 
Table 5. Perception on Antibiotic Use

\begin{tabular}{ll}
\hline Variable & $\begin{array}{c}\text { Frequency (Percentage) } \\
\mathbf{N}(\%)\end{array}$ \\
\hline $\begin{array}{l}\text { When do you think you should stop taking antibiotic? } \\
\text { When I feel better }\end{array}$ & $99(22.00)$ \\
When I have completed the dose as instructed & $326(72.44)$ \\
Don't know & $18(4.00)$ \\
Is it okay to buy the same antibiotic that you have used before when you \\
have similar complaint in the past & $205(45.56)$ \\
Yes & $153(34.00)$ \\
No & $82(18.22)$ \\
Can't say & \\
Is it okay to use antibiotic given to a friend or family as long as they were & \\
used to treat the same illness & $130(29.89)$ \\
Yes & $241(53.56)$ \\
No & $68(15.11)$ \\
Can't say & \\
\hline
\end{tabular}

In Table 6, participant's perception on antibiotic resistance is outlined. It appears that majority [326 (71.78\%)] of the respondents have heard about antibiotic resistance, and more than half of them seem to have some knowledge on what antibiotic resistance is and some factors that encourage it. For example, $278(61.78 \%)$ of the respondents agree that resistance to antibiotics can occur if full treatment with the antibiotic is not completed, while more than half of them [256 (56.89\%)] realize that antibiotic resistance is an issue in Nigeria. 
Table 6. perception on Antibiotic Resistance

\begin{tabular}{|c|c|}
\hline Variable & $\begin{array}{l}\text { Frequency (Percentage) } \\
\quad \text { N }(\%)\end{array}$ \\
\hline \multicolumn{2}{|c|}{ Have you heard of antibiotic resistance before } \\
\hline Yes & $326(71.78)$ \\
\hline No & $118(26.22)$ \\
\hline \multicolumn{2}{|c|}{ Antibiotic resistance occur when the body become resistant to them and they } \\
\hline no longer work well & $295(65.56)$ \\
\hline True & $30(6.67$ \\
\hline False & $91(20.22)$ \\
\hline \multicolumn{2}{|l|}{ Can’t say } \\
\hline \multicolumn{2}{|c|}{$\begin{array}{l}\text { If bacteria are resistant to antibiotic it can become difficult or impossible to } \\
\text { treat infections they cause }\end{array}$} \\
\hline True & $308(68.44)$ \\
\hline False & $18(4.00)$ \\
\hline Can’t say & $84(18.67)$ \\
\hline \multicolumn{2}{|c|}{ Many infections are becoming resistant to antibiotics } \\
\hline True & $289(64.22)$ \\
\hline False & $24(5.33)$ \\
\hline Can’t say & $98(21.78)$ \\
\hline \multicolumn{2}{|c|}{ Antibiotic resistance is an issue in Nigeria } \\
\hline True & $249(55.33)$ \\
\hline False & $23(5.11)$ \\
\hline Can’t say & $138(30.67)$ \\
\hline \multicolumn{2}{|c|}{ Antibiotic resistance can occur if antibiotic are taken when they are not needed } \\
\hline True & $256(58.89)$ \\
\hline False & $36(8.00)$ \\
\hline Can’t say & $121926.89)$ \\
\hline \multicolumn{2}{|c|}{$\begin{array}{l}\text { Antibiotic resistance can occur when the full treatment of antibiotic is not } \\
\text { completed }\end{array}$} \\
\hline True & $278(61.78)$ \\
\hline False & $28(6.22)$ \\
\hline Can't & $114(25.33)$ \\
\hline
\end{tabular}

\section{DISCUSSION}

This study investigated the accessibility and use of antibiotics by a section of the public who visit community pharmacies. Prevalence of antibiotic use from the study participants is high, it can be deduced from the results of this study that many participants are involved in the frequent usage of antibiotics, as about half of the participants had used antibiotics within a month of their current visit to the pharmacy, and also had an antibiotic among the medications they got from their current visit. This trend could be attributed to the fact that the presumed infection or disease that the respondents were treating still persisted. It can be inferred that either they were treating the condition with the wrong drug (antibiotic) or resistance to the antibiotic has occurred, this assumption is further strengthened with the fact that more than half of the participants did not conduct a laboratory investigation before taking the antibiotics (Kuehn, 2013). Studies on antibiotic use by the public have shown that using antibiotic to treat the wrong infection or disease condition is rampart. In Southwestern Nigeria, a study revealed high usage of antibiotics for treating menstrual symptoms by women (Amy et al., 2010), other regions of the country have reported high usage and self-medication with antibiotics. In Northwestern Nigeria among university undergraduates, authors in a study found that more than $60 \%$ of their participants used antibiotics irrationally, similar findings was reported in a rural setting (Olumide et al., 
2018; Abdulraheem et al., 2016). This trend is common in Low and Middle-Income Countries (LMICs). In Congo, about $67.8 \%$ of patients visiting pharmacies bought antimicrobials without a prescription, either on demand by patient or given by the dispensers (Aimerance et al., 2020). In a systematic review of 85 studies, 59 of which was done in LMICs, found that more than $60 \%$ of antibiotics were dispensed without a prescription in 49 (83\%) of the studies (Wertheim et al., 2017).

Several factors are responsible for increase public usage of antibiotics in Nigeria and other LMICs. Overthe-counter sale of antibiotics, the cost of medical consultation, low satisfaction with medical practitioners, misconceptions regarding the efficacy of antibiotics, severity of illness, economic status, past successful antibiotic use and educational level are some contributory factors. High perceived appropriateness of self-medication with antibiotics and attitudes favouring antibiotic use for minor ailments are also predisposing factors for use of selfmedication (Cliodna et al., 2007; Larissa et al.,2008). The perceived availability of antibiotics from pharmacies without a prescription has been the main enabling factor at the individual level, in this study, it seems that more participants visit community pharmacies more than hospitals, as majority of the participants got antibiotics from pharmacies or on pharmacist's recommendation compared to the hospital, even patent medicine dealers have more patronage than hospitals as seen in this study. According to Nigeria's legislation, antibiotics and other antibacterial should only be dispensed with prescription. However, a combination of factors ranging from a shortage of licensed prescribers, pressure to meet up in community pharmacies with some employed dispensers who lack pharmacotherapeutics and appropriate dispensing training, poor access to quality medicines in some areas, to proliferation of under-regulated patent medicine vendor, drug markets and hawkers among others, means that Nigeria suffers severe access problems whilst simultaneously facing a crisis of irrational drug use. Drug misuse extends to the agricultural sector where antimicrobials are liberally used therapeutically and for growth promotion. All of these druguse problems are exacerbating resistance and complicating infectious disease management. Enforcement of the laws regulating the sale of antibiotics will help in curtailing the health danger posed by antibiotic resistance and some of its causes (Goossens et al., 2006; Jones et al., 2008; FDA 2013). It is noteworthy that majority of the respondents in this study are quite knowledgeable regarding the issue of antimicrobial (antibiotic) resistance and the fact that it is a serious issue in Nigeria, thus calling out that their use should be regulated.

Dispensing regulations for prescribed antibiotics in pharmacies is another enabling factor. Dispensing antibiotics per package size can produce leftovers, which, in a previous study, have been shown to substantially contribute to self-medication, with $36 \%$ of those who self-medicated using leftovers (Larissa et al., 2008; Nga et al., 2021; Olumide et al., 2018). In this study, some participants used left over antibiotics. To reduce self-medication with leftovers antibiotics, it is suggested that prescribed antibiotics should not be dispensed according to the package size. Dispensing exact numbers of antibiotic tablets in pharmacies as implemented in some countries such as the UK, the Netherlands, Czech Republic and Israel, as well as in the USA, could be promoted in other countries (Larissa et al., 2008). While in other countries like Bangladesh, Ghana, and Vietnam, unused antibiotics could be returned and refunded (Nga et al., 2021).

Participants in this research used antibiotics for ailments such as urinary tract infections, malaria, typhoid fever, cough (upper respiratory tract infections and fever, with the highest usage for malaria infection likely with antimalarial drug. Previous studies show a wide range of illnesses that patients use antibiotics for as self-medication to include gastrointestinal, respiratory, genitourinary, skin, fever, typhoid, malaria and dental illnesses (Olumide et al.,2018; Abdulraheem et al.,2016; Aimerance et al., 2020). Results from this study on high usage of antibiotics for 
malaria treatment is quite disturbing, it further explains the serial use of antibiotics by the participants (Cliodna $e t$ al.,2007). Aside exposing the misconception that antibiotics treat varied disease conditions including malaria, the frequent use for malaria exposes patients and the public to resistance, since malaria is an infection that is recurring and some patients will have need to treat malaria very often. The objective of permanently changing public perception, and behavior of antimicrobial usage is necessary in the light of the growing AMR crisis. However, such an initiative will require coordination at local, national, and global levels to ensure a consistent "message" and also culturally appropriate local implementation (Carolyn et al., 2014). Such behavioral campaign should target ways to lessen the demand for the immediate application of antimicrobials for non-acute use, discouraging the public from irrational use of antibiotics by enlightening them on the dangers of antimicrobial resistance, and encourage the use of appropriate diagnostics. These measures in addition to promoting appropriate prescribing through regulation will in the long run preserve the limited antibiotics available.

\section{CONCLUSION}

This study reveals a high use of antibiotics without a prescription, partly due to easy access from community pharmacy outlets. The need for regulation of antibiotic prescription in Nigeria is crucial in slowing the rate of resistance. Participant's use of antibiotics for malaria treatment is a public health concern with respect to tackling antimicrobial resistance; measures to increase public behavioral change towards antibiotic use can help to forestall this menace.

\section{ACKNOWLEGDMENT}

The authors express their gratitude to all community pharmacy owners used for this study for granting permission to use their facilities, and all study participants for their willingness to participate.

\section{CONFLICT OF INTEREST}

The authors declare no conflict of interest 


\section{REFERENCES}

Abdulraheem I.S ,A. Adegboye A. , A. Fatiregun (2016) Self-medication with Antibiotics: Empirical Evidence from a Nigerian Rural Population. Journal of Pharmaceutical Research International, 11(5):1-13. DOI; 10.9734/BJPR/2016/25268

Aimerance Bahati Ntizala, Tresor Yoshua Mulume, Bernard Lukundja Runyeruka, Antoine Sadiki Kishabongo (2020). Antibiotic Dispensing Practices in Community Pharmacies: A Major Health Concern in the Eastern Democratic Republic of Congo. Journal of Pharmaceutical Research International, 32(4): 33-44 DOI: 10.9734/jpri/2020/v32i1430603

Amy R Sapkota, Morenike E Coker, Rachel E Rosenberg Goldstein, Nancy L Atkinson, Shauna J Sweet, Priscilla O Sopeju, Modupe T Ojo, Elizabeth Otivhia, Olayemi O Ayepola (2010). Self-medication with antibiotics for the treatment of menstrual symptoms in southwest Nigeria: a cross-sectional study. BioMed Central Public Health, 10:610 doi: 10.1186/1471-2458-10-610

Ayukekbong J.A., Ntemgwa M., Atabe A.N (2017). The threat of antimicrobial resistance in developing countries: Causes and control strategies. Antimicrobial Resistance Infection Control; 6:47. doi: 10.1186/s13756-017-0208-x

Carolyn Anne Michael, and Maurizio Labbate (2014). School of Medical and Molecular Biosciences, University of Technology, Sydney. The antimicrobial resistance crisis: causes, consequences, and management. Frontiers in Public Health, 2:145 https://doi.org/10.3389/fpubh.2014.00145

Cliodna AM, McNulty P, Boyle P, Nichols T, Clappison P, Davey P (2007). The public's attitudes to and compliance with antibiotics. Journal of Antimicrobial Chemotherapy 60(Suppl 1):63-doi;810.1093/jac/dkm161

Food and Drug Administration (2013). Phasing Out Certain Antibiotic Use in Farm Animals. Available from: http://www.fda.gov/downloads/ForConsumers/ConsumerUpdates/UCM378197.pdf Accessed July 2021

Goossens H, Guillemot D, Ferech M, Schlemmer B, Costers M, Van Breda M, et al., (2006). National campaigns to improve antibiotic use. European Journal of Clinical Pharmacology 62:373-910. Doi:1007/s00228-005-0094-7

Jones KE, Patel NG, Levy MA, Storeygar A, Balk D, Gittleman JL, et al., (2008). Global trends in emerging infectious diseases. Nature 451(21):990-310.doi:1038/nature06536

Kuehn BM. IDSA (2013): Better, faster diagnostics for infectious diseases needed to curb overtreatment, antibiotic resistance. Journal of American Medical Association 310(22):2385-2386 doi:10.1001/jama.2013.283828

Larissa Grigoryan, Johannes G. M. Burgerhof, John E. Degener, Reginald Deschepper, Cecilia Stålsby Lundborg, Dominique L. Monnet, Elizabeth A. Scicluna, Joan Birkin, Flora M. Haaijer-Ruskamp_ (2008). Determinants of selfmedication with antibiotics in Europe: the impact of beliefs, country wealth and the healthcare system. Journal of Antimicrobial Chemotherapy; 61(5):1172-1179, 
Nga T T Do,Huong T L Vu, Chuc T K Nguyen, Sureeporn Punpuing, Wasif Ali Khan, Prof Margaret Gyapong, et al., (2021). Community-based antibiotic access and use in six low-income and middle-income countries: a mixed-method approach. The lancet Global Health 9(5):e610-e619

Olumide Ajibola, Olusola Akintoye Omisakin, Anthonius Anayochukwu Eze, and Semeeh Akinwale Omoleke (2018). Self-Medication with Antibiotics, Attitude and Knowledge of Antibiotic Resistance among Community Residents and Undergraduate Students in Northwest Nigeria. Diseases; 6(2): 32.

Wertheim HFL, Chuc NTK, John K, Osman S (2017). Community-level antibiotic access and use (ABACUS) in lowand middle-income countries: finding targets for social interventions to improve appropriate antimicrobial use-an observational multi-centre study. Wellcome Open Research; 2: 5

World Health Organization (2017). Antibiotic resistance, Fact sheet [Internet]. Available: http://www.who.int/mediacentre/factsheets/antibiotic-resistance/en/ Accessed July 25 2021

World Health Organization (2015). WHO | Rational use of medicines. WHO. World Health Organization; Available: https://www.who.int/medicines/areas/rational_use/en/ Accessed July $25^{\text {th }} 2021$

World Health Organization (2001). WHO Global Strategy for Containment of Antimicrobial Resistance [Internet]. Available: https://www.who.int/drugresistance/WHO_Global_Strategy_English.pdf. Accessed July $25^{\text {th }} 2021$. 